\title{
Dynamic Analysis of a Fiber-Reinforced Composite Beam under a Moving Load by the Ritz Method
}

\author{
Şeref D. Akbaş ${ }^{1}$, Hakan Ersoy ${ }^{2}(1)$, Bekir Akgöz ${ }^{3}(1)$ and Ömer Civalek ${ }^{3,4, *}$ \\ 1 Department of Civil Engineering, Bursa Technical University, 16310 Bursa, Turkey; \\ serefda@yahoo.com or seref.akbas@btu.edu.tr \\ 2 Division of Mechanics, Department of Mechanical Engineering, Akdeniz University, 07058 Antalya, Turkey; \\ hakanersoy@akdeniz.edu.tr \\ 3 Division of Mechanics, Department of Civil Engineering, Akdeniz University, 07058 Antalya, Turkey; \\ bekirakgoz@akdeniz.edu.tr \\ 4 Department of Medical Research, China Medical University Hospital, China Medical University, \\ Taichung 40447, Taiwan \\ * Correspondence: civalek@yahoo.com or omer@mail.cmuh.org.tw
}

Citation: Akbaş, Ş.D.; Ersoy, H.; Akgöz, B.; Civalek, Ö. Dynamic

Analysis of a Fiber-Reinforced

Composite Beam under a Moving Load by the Ritz Method. Mathematics 2021, 9, 1048. https:// doi.org/10.3390/math9091048

Academic Editors: Theodore E. Simos and Charampos Tsitouras

Received: 14 April 2021

Accepted: 4 May 2021

Published: 6 May 2021

Publisher's Note: MDPI stays neutral with regard to jurisdictional claims in published maps and institutional affiliations.

Copyright: (c) 2021 by the authors. Licensee MDPI, Basel, Switzerland. This article is an open access article distributed under the terms and conditions of the Creative Commons Attribution (CC BY) license (https:// creativecommons.org/licenses/by/ $4.0 /)$.

\begin{abstract}
This paper presents the dynamic responses of a fiber-reinforced composite beam under a moving load. The Timoshenko beam theory was employed to analyze the kinematics of the composite beam. The constitutive equations for motion were obtained by utilizing the Lagrange procedure. The Ritz method with polynomial functions was employed to solve the resulting equations in conjunction with the Newmark average acceleration method (NAAM). The influence of fiber orientation angle, volume fraction, and velocity of the moving load on the dynamic responses of the fiber-reinforced nonhomogeneous beam is presented and discussed.
\end{abstract}

Keywords: moving load problems; fiber-reinforced composite materials; Timoshenko beams; Ritz method

\section{Introduction}

Conventional engineering materials may be classified as metals, polymers, ceramics, and composites. Metals have high rigidity, ductility, mechanical strength, and thermal stability. They are also exceedingly good conductors of electricity and heat. Polymers have become one of the widely used engineering materials due to their lower density, easy machinability, and corrosion resistance compared to other materials. Ceramics contain strong covalent bonds and have almost zero thermal and electrical conductivities and extremely good thermal stability and hardness.

A composite material is any solid consisting of at least two components contained in separate phases. Wood is a natural composition of cellulose fibers in a lignin matrix. Another well-known example of man-made composite material is reinforced concrete. Steel and concrete maintain their individual characteristics in the resulting composite structure. However, because they work in harmony, the steel carries tension loads, and the concrete withstands compression loads. The main advantages of composite materials include excellent strength-to-weight and stiffness-to-weight ratios. Additionally, composite materials may have excellent resistance to corrosion.

Fiber-reinforced composite (FRC) structures are used in various engineering applications, for example, airplanes, machine, marine, and civil engineering projects, because of their higher strength-to-weight ratios, greater lightweight, and better ductile properties [1-9]. The main practical applications of FRC structures comprise molded car panels, helicopter and wind turbine blades, tennis rackets, ski-poles, and prosthesis. More details can be found in $[10,11]$. Issues associated with a moving load are very important in FRC structures used in bridges, roads, railways structures. With dynamically moving loads, the mechanical behavior of structures varies significantly [12-18]. Therefore, understanding 
the dynamical behavior of FRC structures is crucial for their design. Some works on the mechanical analysis of FRC beams are reported below.

A dynamic analysis of beams reinforced with fibers was performed by Teoh and Huang [19]. Bending and stability responses of thin-walled beams reinforced with cast polyamide, carbon, and glass fibers were perused by Eksi et al. [20]. The vibrational response of a laminated beam with a $\mathrm{SiC}$ particle-reinforced Al6082 matrix in a magnetorheological fluid core was examined [21]. Large-amplitude vibration analyses of laminated imperfect FRC beams were performed by Jin et al. [22]. Post-buckling and large deflection analyses of an FRC beam were made with the finite element method by Akbas [23-25]. In addition, the mechanical responses of composite beams reinforced with carbon fiber have attracted the attention of researchers [26-29].

On the other hand, carbon nanotubes (CNTs) have also been used as a reinforcement material. Due to the extraordinary properties of CNTs, many studies have been performed on their mechanical characteristics [30-33]. The bending and buckling responses of a nanocomposite beam reinforced with SWCNT were comprehensively examined [34]. Ke et al. [35] performed a large-amplitude vibration analysis of nonhomogeneous CNTreinforced beams on the basis of the Timoshenko beam theory. Yas and Samadi [36] perused the dynamic and stability responses of CNT-reinforced composite beams surrounded by an elastic medium by GDQM. More details about nanocomposite beams reinforced with CNTs can be found in other related works [37-49]. Moreover, the vibration and buckling behaviors of nanocomposite beams reinforced with graphene nanoplatelets were studied [50-53].

As seen above, there are a number of studies on the mechanical analysis of reinforced composite beams in the scientific literature. However, works about the dynamic analysis of FRC beams under a moving load are very limited. To the best of the authors' knowledge, the dynamical response of fiber-reinforced composite beams subjected to a moving load using the Newmark average acceleration and Ritz methods was examined for the first time in a simply supported boundary condition. In the present study, dynamically moving issues related to an FRC beam are investigated using the Timoshenko beam theory and Ritz method. The governing equations for a reinforced composite beam in dynamic analysis were obtained by using the Lagrange procedure. NAAM was utilized to solve the forced vibration problem in time. The influence of fiber orientation angles, volume fraction, and velocity of the moving load on the dynamical behavior of the FRC beam is presented.

\section{Materials and Methods}

In Figure 1, a simply supported FRC beam with length $L$, height $h$, and width $b$ under a moving load is shown. $Q$ and $\mathrm{v}_{Q}$ represent the magnitude and the constant velocity of the load, respectively.

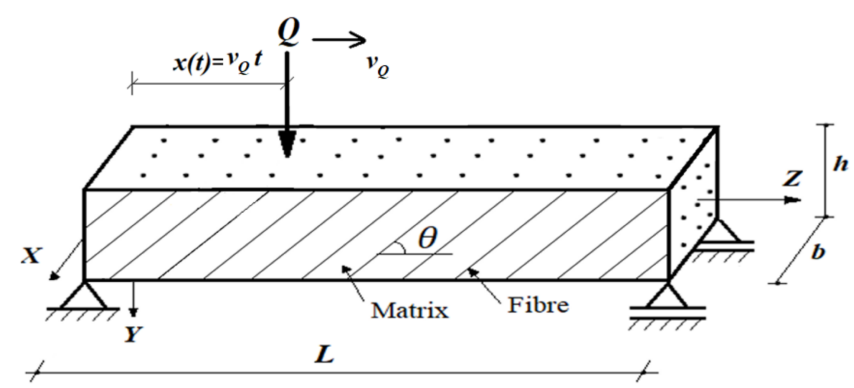

Figure 1. A simply supported FRC beam under a moving load.

The axial $\left(\varepsilon_{z}\right)$ and shear $\left(\gamma_{z y}\right)$ strains can be written based on the first-order shear deformation beam theory as

$$
\varepsilon_{z}=\frac{\partial u_{0}}{\partial z}-Y \frac{\partial \varnothing}{\partial z}
$$




$$
\gamma_{z y}=\frac{\partial u_{0}}{\partial y}+\frac{\partial v_{0}}{\partial z}
$$

where $u_{0}, v_{0}$, and $\varnothing$ denote axial and vertical displacements and rotation, respectively. The constitutive relation is presented as follows

$$
\left\{\begin{array}{c}
\sigma_{z} \\
\sigma_{z y}
\end{array}\right\}=\left[\begin{array}{ll}
\bar{R}_{11} & \bar{R}_{16} \\
\bar{R}_{16} & \bar{R}_{66}
\end{array}\right]\left\{\begin{array}{c}
\varepsilon_{z} \\
\gamma_{z y}
\end{array}\right\}
$$

where $\bar{R}_{i j}$ represents the transformed components of the reduced constitutive tensor. They can be expressed for orthotropic materials as

$$
\begin{gathered}
\bar{R}_{11}=Q_{11} c^{4}+2\left(Q_{12}+2 Q_{66}\right) c^{2} s^{2}+Q_{22} s^{4} \\
\bar{R}_{12}=\left(Q_{11}+Q_{22}-4 Q_{66}\right) s^{2} c^{2}+Q_{12}\left(c^{4}+s^{4}\right) \\
\bar{R}_{16}=\left(Q_{11}-Q_{12}-2 Q_{66}\right) s c^{3}+\left(Q_{12}-Q_{22}+2 Q_{66}\right) s^{3} c \\
\bar{R}_{22}=Q_{11} s^{4}+2\left(Q_{12}+2 Q_{66}\right) s^{2} c^{2}+Q_{22} c^{4} \\
\bar{R}_{26}=\left(Q_{11}-Q_{12}-2 Q_{66}\right) s^{3} c+\left(Q_{12}-Q_{22}+2 Q_{66}\right) s c^{3} \\
\bar{R}_{66}=\left(Q_{11}+Q_{22}-2 Q_{12}-2 Q_{66}\right) s^{2} c^{2}+Q_{66}\left(s^{4}+c^{4}\right)
\end{gathered}
$$

where $c=\cos \theta$, and $s=\sin \theta \cdot \theta$ specifies the fiber orientation angle, and $Q_{i j}$ can be defined as

$$
\begin{gathered}
Q_{11}=\frac{E_{1}}{1-v_{12} v_{21}}, Q_{22}=\frac{E_{2}}{1-v_{12} v_{21}} \\
Q_{12}=Q_{21}=\frac{v_{12} E_{2}}{1-v_{12} v_{21}}=\frac{v_{21} E_{1}}{1-v_{12} v_{21}} \\
Q_{66}=G_{12}
\end{gathered}
$$

where $E_{1}$ and $E_{2}$ are, respectively, the elastic modulus in the $Z$ and $Y$ directions, $v_{12}$ and $v_{21}$ are Poisson's ratios, and $G_{12}$ is the shear modulus in the $Z Y$ plane. The mechanical properties of composite materials can be calculated according to the relations in Equations (5a)-(5e) [54]

$$
\begin{gathered}
E_{1}=E_{f} V_{f}+E_{m}\left(1-V_{f}\right) \\
E_{2}=E_{m}\left[\frac{E_{f}+E_{m}+\left(E_{f}-E_{m}\right) V_{f}}{E_{f}+E_{m}-\left(E_{f}-E_{m}\right) V_{f}}\right] \\
v_{12}=v_{f} V_{f}+v_{m}\left(1-V_{f}\right) \\
G_{12}=G_{m}\left[\frac{G_{f}+G_{m}+\left(G_{f}-G_{m}\right) V_{f}}{G_{f}+G_{m}-\left(G_{f}-G_{m}\right) V_{f}}\right] \\
\rho=\rho_{f} V_{f}+\rho_{m}\left(1-V_{f}\right)
\end{gathered}
$$

where $f$ and $m$ indicate the fiber and matrix, respectively, and $V_{f}$ is the volume fraction of the fiber. Also, $E, G, v$, and $\rho$ denote the material's properties, i.e., Young's modulus, shear modulus, Poisson's ratio, and mass density, respectively.

The strain energy $\left(U_{S}\right)$, kinetic energy $(T)$, and potential energy of the external loads $\left(U_{e}\right)$ can be expressed as

$$
U_{S}=\frac{1}{2} \int_{0}^{L}\left[A_{0}\left(\frac{\partial u_{0}}{\partial z}\right)^{2}+A_{2}\left(\frac{\partial \varnothing}{\partial z}\right)^{2}\right] d Z+\frac{1}{2} \int_{0}^{L} K_{S} B_{0}\left[\left(\frac{\partial v_{0}}{\partial z}\right)^{2}-2 \frac{\partial v_{0}}{\partial z} \varnothing+\varnothing^{2}\right] d Z
$$




$$
T=\frac{1}{2} \int_{0}^{L}\left(I_{0}\left(\frac{\partial u_{0}}{\partial t}\right)^{2}+I_{2}\left(\frac{\partial \varnothing}{\partial t}\right)^{2}+I_{0}\left(\frac{\partial v_{0}}{\partial t}\right)^{2}\right) d Z
$$

where $K_{S}$ is a shear correction factor, chosen as $5 / 6$ in the present study and

$$
A_{0}=\bar{R}_{11} b h, A_{2}=\bar{R}_{11} b h^{3} / 12, B_{0}=\bar{R}_{66} b h, I_{0}=\rho b h, I_{2}=\rho b h^{3} / 12
$$

The Lagrangian function can be written as

$$
I=T-\left(U_{i}+U_{e}\right)
$$

An approximate solution can be achieved as a series of $n$ terms of the following form, according to the Ritz method

$$
\begin{aligned}
& u_{0}(z, t)=\sum_{i=1}^{\infty} d_{n}(t) \varphi_{n}(z) \\
& v_{0}(z, t)=\sum_{i=1}^{\infty} e_{n}(t) \chi_{n}(z) \\
& \varnothing(z, t)=\sum_{i=1}^{\infty} f_{n}(t) \psi_{n}(z)
\end{aligned}
$$

where $d_{\mathrm{n}}, e_{\mathrm{n}}$, and $f_{\mathrm{n}}$ are the unknown time-dependent generalized coordinates, and $\varphi_{n}(z), \chi_{n}(z)$, and $\psi_{n}(z)$ are the admissible functions dependent on the boundary conditions. $\varphi_{n}(z), \chi_{n}(z)$, and $\psi_{n}(z)$ can be written, for a simply supported beam, as

$$
\begin{gathered}
\varphi_{n}(z)=z^{n} \\
\chi_{n}(z)=(L-z) z^{n} \\
\psi_{n}(z)=z^{(n-1)}
\end{gathered}
$$

where $n$ states the order of polynomials in the approximate functions.

Substituting Equations (9a)-(9c) into Equations (6a) and (6b) and then implementing the Lagrange's equation yields Equation (11)

$$
\frac{\partial I}{\partial r_{n}}-\frac{\partial}{\partial t} \frac{\partial I}{\partial \dot{r}_{n}}=0
$$

where $r_{n}$ represents $d_{n}, e_{n}$, and $f_{n}$. The equation of motion is achieved as

$$
[K]\{\mathrm{r}(\mathrm{t})\}+[\mathcal{M}]\{\ddot{\mathrm{r}}(\mathrm{t})\}=\{\mathrm{F}(\mathrm{t})\}
$$

The components of these matrices and vector are presented below

$$
[K]=\left[\begin{array}{lll}
K_{11} & K_{12} & K_{13} \\
K_{21} & K_{22} & K_{23} \\
K_{31} & K_{32} & K_{33}
\end{array}\right]
$$

where

$$
\begin{gathered}
K_{11}=\sum_{i=1}^{n} \sum_{j=1}^{n} \int_{0}^{L} A_{0} \frac{\partial \varphi_{i}}{\partial z} \frac{\partial \varphi_{j}}{\partial z} d z, K_{12}=0, K_{13}=0 \\
K_{21}=0, K_{22}=\sum_{i=1}^{n} \sum_{j=1}^{n} \int_{0}^{L} K_{s} B_{0} \frac{\partial \chi_{i}}{\partial z} \frac{\partial \chi_{j}}{\partial z} d z, K_{23}=-\sum_{i=1}^{n} \sum_{j=1}^{n} \int_{0}^{L} K_{s} B_{0} \frac{\partial \chi_{i}}{\partial z} \psi_{j} d z
\end{gathered}
$$




$$
\begin{gathered}
K_{31}=0, K_{32}=-\sum_{i=1}^{n} \sum_{j=1}^{n} \int_{0}^{L} K_{s} B_{0} \psi_{i} \frac{\partial \chi_{j}}{\partial z} d z \\
K_{33}=\sum_{i=1}^{n} \sum_{j=1}^{n} \int_{0}^{L} A_{2} \frac{\partial \psi_{i}}{\partial z} \frac{\partial \psi_{j}}{\partial z} d z+\sum_{i=1}^{n} \sum_{j=1}^{n} \int_{0}^{L} K_{s} B_{0} \psi_{i} \psi_{j} d z \\
{[\mathcal{M}]=\left[\begin{array}{lll}
\mathcal{M}_{11} & \mathcal{M}_{12} & \mathcal{M}_{13} \\
\mathcal{M}_{21} & \mathcal{M}_{22} & \mathcal{M}_{23} \\
\mathcal{M}_{31} & \mathcal{M}_{32} & \mathcal{M}_{33}
\end{array}\right]}
\end{gathered}
$$

in which

$$
\begin{gathered}
\mathcal{M}_{11}=\sum_{\mathrm{i}=1}^{\mathrm{n}} \sum_{\mathrm{j}=1}^{\mathrm{n}} \int_{0}^{\mathrm{L}} \mathrm{I}_{0} \varphi_{i} \varphi_{j} \mathrm{dz}, \mathcal{M}_{12}=0, \mathcal{M}_{13}=0 \\
\mathcal{M}_{21}=0, \mathcal{M}_{22}=\sum_{\mathrm{I}=1}^{\mathrm{n}} \sum_{\mathrm{j}=1}^{\mathrm{n}} \int_{0}^{\mathrm{L}} \mathrm{I}_{0} \chi_{i} \chi_{j} \mathrm{dz}, \mathcal{M}_{23}=0 \\
\mathcal{M}_{31}=0, \mathcal{M}_{32}=0 \\
\mathcal{M}_{33}=\sum_{\mathrm{i}=1}^{\mathrm{n}} \sum_{j=1}^{\mathrm{n}} \int_{0}^{\mathrm{L}} \mathrm{I}_{2} \psi_{i} \psi_{j} \mathrm{dz} \\
\{\mathrm{F}(\mathrm{t})\}=Q \chi_{j}\left(\mathrm{v}_{\mathrm{Q}} \mathrm{t}\right) 0 \leq \mathrm{t} \leq \frac{\mathrm{L}}{\mathrm{v}_{\mathrm{Q}}}
\end{gathered}
$$

Equation (12) can be solved within the time domain by NAAM. The procedure of NAAM is presented as follows

$$
[\bar{K}(t)]\left\{d_{n}\right\}_{r+1}=\{\bar{F}(t)\}
$$

where

$$
\begin{gathered}
{[\bar{K}(t)]=[K]+a_{0}[\mathcal{M}]} \\
\{\bar{F}(t)\}=\{\bar{F}(t)\}_{r+1}+[\mathcal{M}]\left(a_{0}\left\{d_{n}\right\}_{r}+a_{1}\left\{\dot{d}_{n}\right\}_{r}+a_{2}\left\{\ddot{d}_{n}\right\}_{r}\right)
\end{gathered}
$$

where

$$
a_{0}=\frac{1}{\beta \Delta t^{2}}, a_{1}=\frac{1}{\beta \Delta t}, a_{2}=\frac{1-2 \beta}{\beta},
$$

where $\alpha=0.5, \beta=0.25$. After evaluating $\left\{d_{n}\right\}_{r+1}$ at time $t_{r+1}=t_{r}+\Delta t$, the acceleration and velocity vectors can be determined by

$$
\begin{gathered}
\left\{\ddot{d}_{n}\right\}_{j+1}=a_{0}\left(\left\{d_{n}\right\}_{r+1}-\left\{d_{n}\right\}_{r}\right)-a_{1}\left\{\dot{d}_{n}\right\}_{r}-a_{2}\left\{\ddot{d}_{n}\right\}_{r} \\
\left\{\dot{d}_{n}\right\}_{r+1}=\left\{\dot{d}_{n}\right\}_{r}+a_{3}\left\{\ddot{d}_{n}\right\}_{r}+a_{4}\left\{\ddot{d}_{n}\right\}_{r+1}
\end{gathered}
$$

where $a_{3}=(1-\alpha) \Delta t$, and $a_{4}=\alpha \Delta t$.

The dimensionless transversal displacement and time are respectively presented as follows

$$
\bar{v}=\frac{v}{L}, t^{*}=\frac{t}{L} \mathrm{v}_{\mathrm{Q}}
$$

\section{Numerical Results}

In this section, dynamical displacements of the FRC simply supported beam under a moving load are presented and discussed according to different material and load parameters. In the numerical examples, the materials of the beams were selected as consisting of a graphite fiber-reinforced polyamide composite, and its parameters were as 
follows [55]: $E_{m}=2.756 \mathrm{GPa}, E_{f}=275.6 \mathrm{GPa}, G_{m}=1.036 \mathrm{GPa}, G_{f}=114.8 \mathrm{GPa}, v_{m}=0.33$, $v_{f}=0.2, \rho_{m}=1600 \mathrm{~kg} / \mathrm{m}^{3}, \rho_{f}=1900 \mathrm{~kg} / \mathrm{m}^{3}$. The geometry properties of the beam were selected as $\mathrm{b}=\mathrm{h}=0.1 \mathrm{~m}$, and $\mathrm{L}=10 \mathrm{~h}$. The amplitude of the dynamic load was selected as $Q_{0}=1 \mathrm{kN}$.

Firstly, a convergence study was performed to determine the suitable number of polynomials, as shown in Figure 2. The maximum dimensionless dynamic displacements at midspan of the FRC beam under a moving load were calculated for $V_{f}=0.3, \theta=10^{\circ}$, $V_{Q}=10 \mathrm{~m} / \mathrm{s}$. It Figure 2, it can be observed that the number of polynomials has a crucial effect on the convergence of the dynamic displacements. It is also apparent that an increase in the number of polynomials yields an increase in the maximum dynamic displacements and the divergence between the maximum dynamic displacements diminishes for a higher number of polynomials, i.e., for $n>9$. Consequently, the number of polynomials is chosen as 10 in the numerical results.

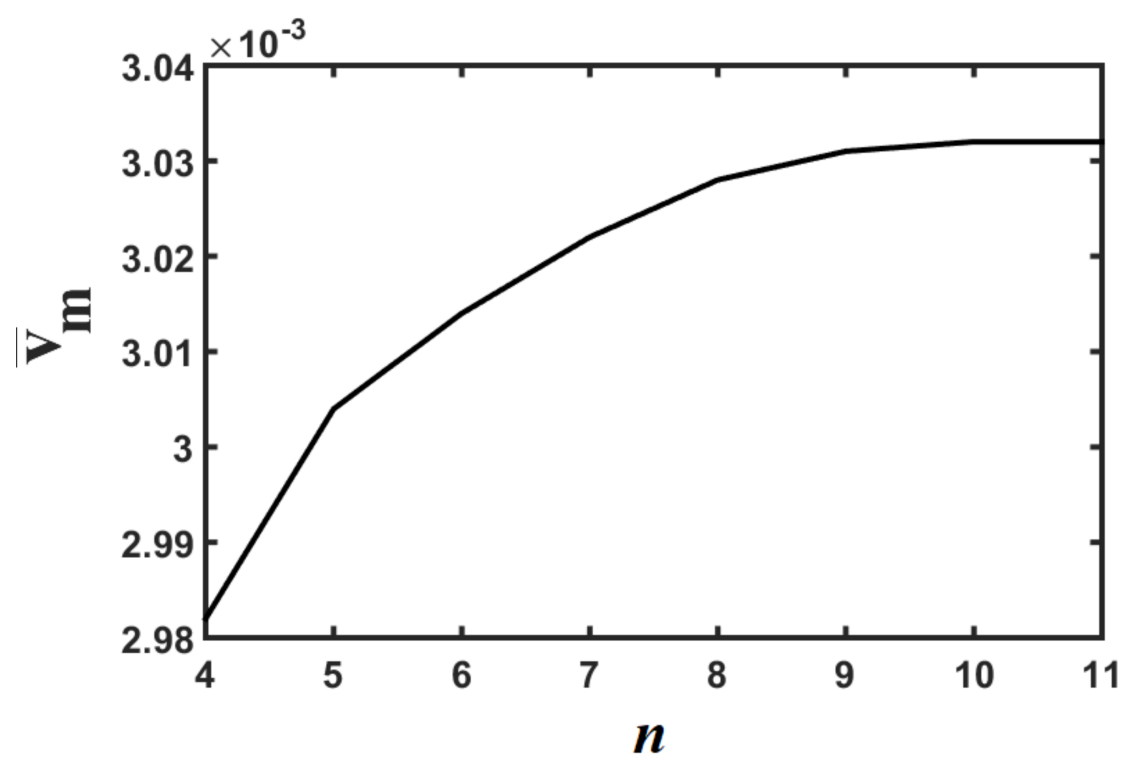

Figure 2. Convergence of maximum dimensionless dynamic displacements $\left(\bar{v}_{m}\right)$ of the FRC beam under a moving load for $V_{f}=0.3, \theta=10^{\circ}, V_{Q}=10 \mathrm{~m} / \mathrm{s}$.

Then, in order to demonstrate the accuracy and validity of the present analysis, the results were compared with those of a previous work available in the literature. For this, the dynamic lateral displacements at midspan of a homogeneous and isotropic beam under a moving load were compared with [56] in Figure 3. For a validation purpose, the material parameters were chosen as $E=210 \mathrm{GPa}, \rho=7800 \mathrm{~kg} / \mathrm{m}^{3}, v=0.3, v_{f}=30 \mathrm{~m} / \mathrm{s}$. As shown in this figure, it is clear that our findings are in agreement with other established results.

In Figure 4, the effects of the fiber orientation angle $(\theta)$ on the dimensionless lateral dynamical displacements at midspan $\left(\bar{v}_{m}\right)$ of FRC beams are presented for the different values of $\theta$ and velocity of loads in the dimensionless time history for $V_{f}=0.3$. The dimensionless displacements $(\bar{v})$ and time $\left(t^{*}\right)$ quantities defined in Equation (24) were used in the time history graphs. As seen in Figure 4, the dynamical lateral dimensionless displacements of the FRC beam increased with an increment in $\theta$. The bending rigidity decreased when increasing the fiber orientation angles according to Equation 3, so the displacements increased. In addition, the velocity of the load had an important influence on the effects of the fiber orientation angle. With different values of the velocity of the load, the effects of the fiber orientation angle on the dynamic results changed considerably. For lower values of the velocity of the load, the effect of the fiber orientation angle were larger than for higher load velocities. 


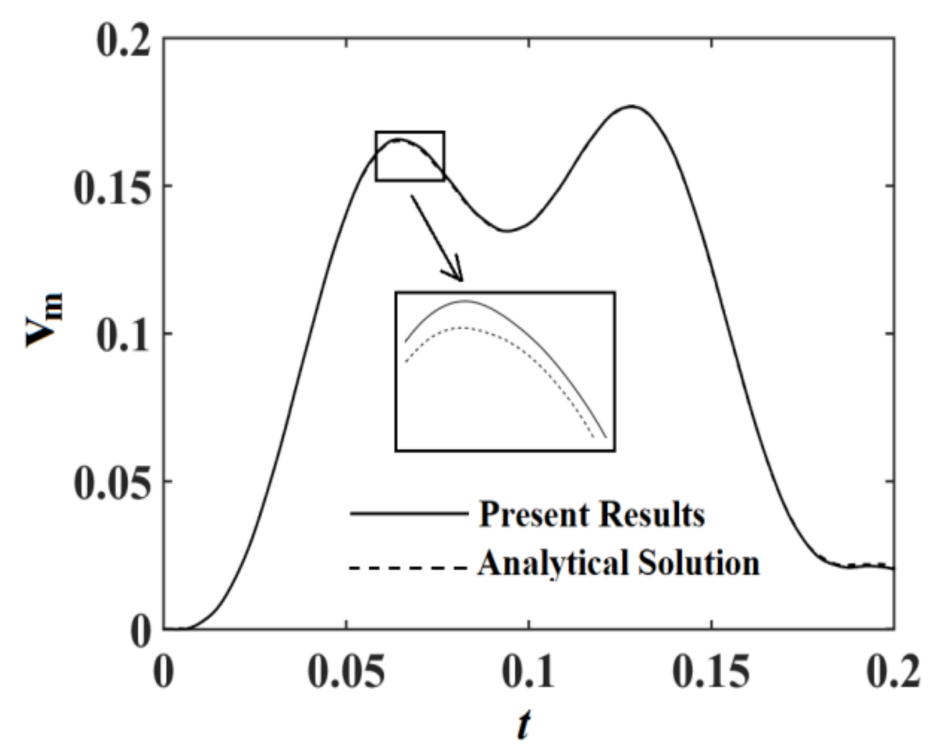

Figure 3. Dynamic lateral displacements at midspan $\left(\mathrm{v}_{\mathrm{m}}\right)$ of a homogeneous and isotropic beam under a moving load.

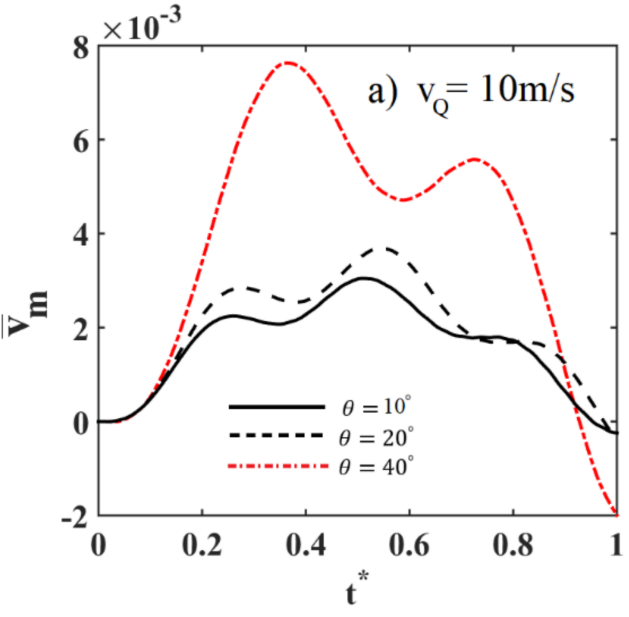

(a)

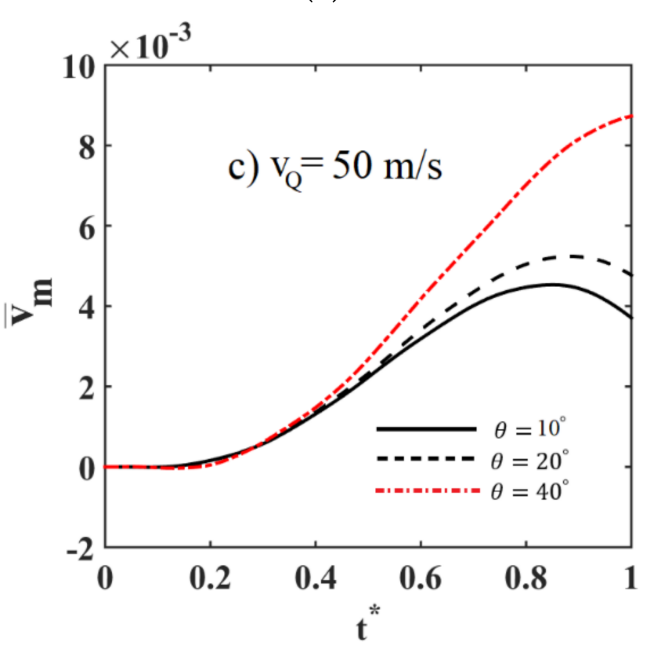

(c)

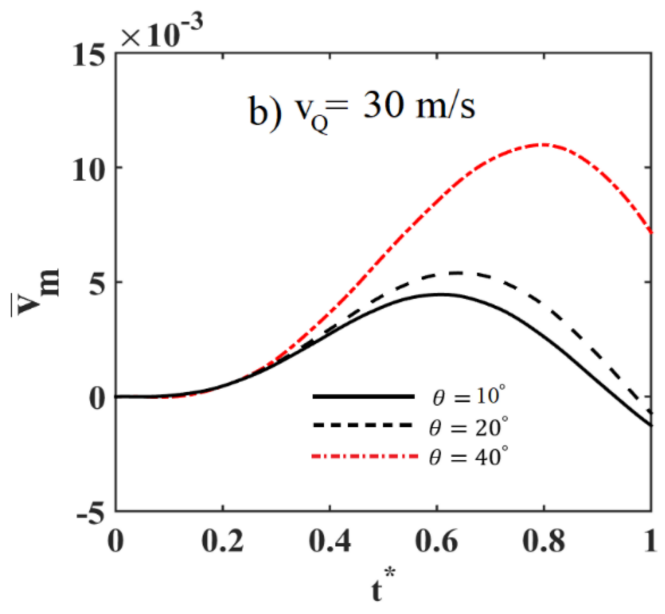

(b)

Figure 4. Time history of dimensionless dynamic displacements at midspan of the FRC beam under a moving load for different values of the fiber orientation angle $(\theta)$. 
The influences of $V_{f}$ and $V_{Q}$ on the dimensionless dynamic displacements of a simply supported FRC beam are depicted within time history in Figure 5 for $\theta=30^{\circ}$. It is seen from Figure 5 that increasing volume fraction of the fiber decreased the dynamical displacements, as expected. It is also evident that the dimensionless dynamic displacements evaluated for $V_{f}=0.1$ and $V_{f}=0.2$ were close to each other, while those for $V_{f}=0.3$ were very different. In addition, the effects of the volume fraction of fiber on the dynamic responses varied considerably for different values of load's velocity. For different values of $V_{Q}$, the behavior of the fibers in the dynamic response changed. For example, for $V_{Q}=10 \mathrm{~m} / \mathrm{s}$ and $t^{*}=1$, the effects of the volume fraction of fiber were very different from those for other $V_{Q}$ and $t^{*}$. This revealed that $V_{Q}$ has an important effect on the dynamic responses of FRC beams.

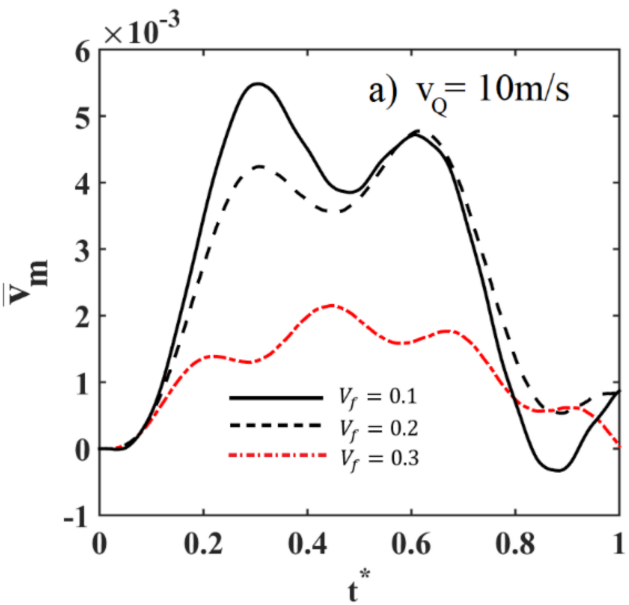

(a)

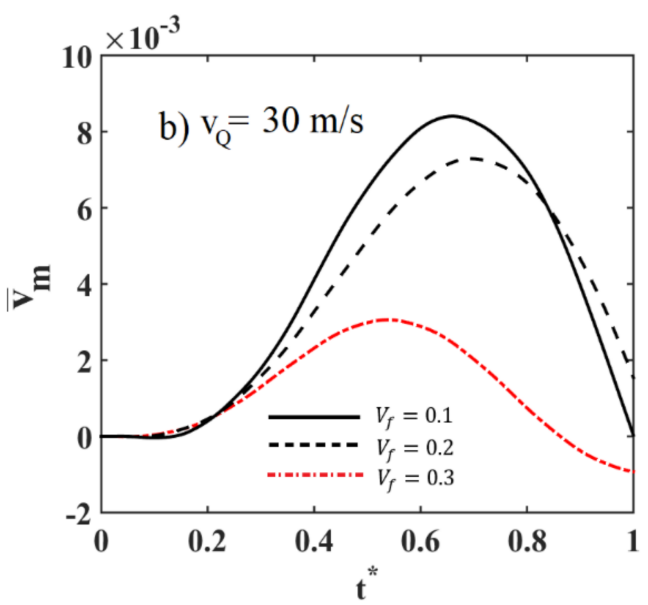

(b)

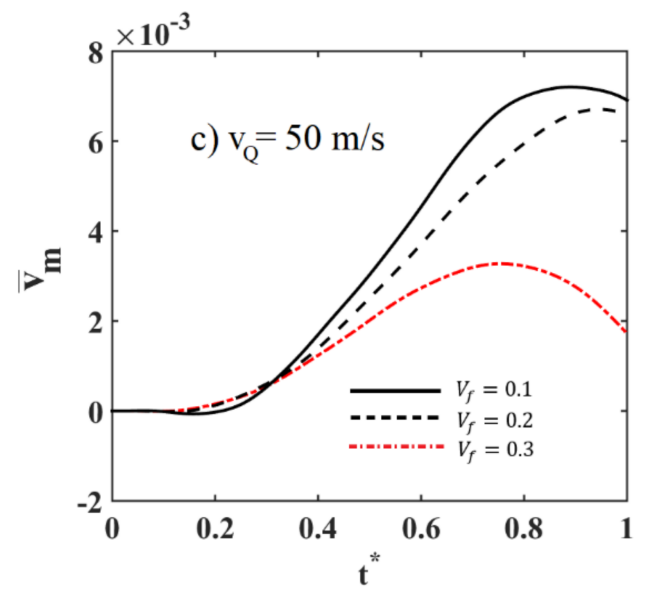

(c)

Figure 5. Time history of dimensionless dynamic displacements at midspan of the FRC beam under a moving load for different values of the volume fraction of fiber $\left(V_{f}\right)$.

\section{Conclusions}

A dynamic analysis of an FRC simply supported beam under a moving load was carried out based on the Timoshenko beam theory by using the Ritz method. The governing equations in motion were achieved with the aid of the Lagrange procedure. The Newmark average acceleration procedure was employed in the time history. The influence of fiber orientation angle, volume fraction, and load velocity on the dynamic displacements of the FRC beam was investigated in detail. It is concluded from the reported results that the fiber orientation angle and the volume fraction exert an important effect on the dynamic responses of FRC beams under a moving load. With variations in these parameters, the dynamic responses of the FRC beam change significantly. By changing the values of 
load velocity, the effects of fiber orientation angle and volume fraction on the dynamical responses change considerably.

Author Contributions: Conceptualization, Ö.C. and Ş.D.A.; methodology, Ş.D.A.; software, Ş.D.A.; validation, Ş.D.A. and H.E.; formal analysis, S..D.A.; investigation, Ş.D.A; resources, B.A and H.E.; data curation, H.E.; writing—original draft preparation, S..D.A and B.A; writing-review and editing, Ö.C and B.A.; visualization, B.A. and H.E; supervision, Ö.C.; project administration, Ö.C. and H.E.; funding acquisition, Ö.C. and H.E. All authors have read and agreed to the published version of the manuscript.

Funding: This research received no external funding.

Institutional Review Board Statement: Not applicable.

Informed Consent Statement: Not applicable.

Data Availability Statement: Not applicable.

Conflicts of Interest: The authors declare no conflict of interest.

\section{References}

1. Shariat, M.; Shariati, M.; Madadi, A.; Wakil, K. Computational Lagrangian multiplier method by using for optimization and sensitivity analysis of rectangular reinforced concrete beams. Steel Compos. Struct. 2018, 29, 243-256. [CrossRef]

2. Luo, Z.Y.; Sinaei, H.; Ibrahim, Z.; Shariati, M.; Jumaat, Z;; Wakil, K.; Pham, B.T.; Mohamad, E.T;; Khorami, M. Computational and experimental analysis of beam to column joints reinforced with CFRP plates. Steel Compos. Struct. 2019, 30, 271-280. [CrossRef]

3. Huang, W.; Yan, W.; He, W.; Wang, K.; Long, L.; He, M.; Qin, S.; Yu, J. Synergistic flame-retardant effect of DOPO-based derivative and organo-montmorillonite on glass-fiber-reinforced polyamide 6 T. Polym. Adv. Technol. 2020, 31, 2083-2093. [CrossRef]

4. Souza, P.R.; Nunes, C.S.; Freitas, A.R.; Belinato, J.R.; Pilau, E.J; Fajardo, A.R.; Da Silva Filho, E.A.; Schreiner, W.H.; Muniz, E.C. Sub- and supercritical D-limonene technology as a green process to recover glass fibres from glass fibre-reinforced polyester composites. J. Clean. Prod. 2020, 254, 119984. [CrossRef]

5. Amiri, A.; Krosbakken, T.; Schoen, W.; Theisen, D.; A Ulven, C. Design and manufacturing of a hybrid flax/carbon fiber composite bicycle frame. Proc. Inst. Mech. Eng. Part P 2018, 232, 28-38. [CrossRef]

6. Lawcock, G.; Ye, L.; Mai, Y.W. Novel fiber-reinforced metal laminates for aerospace applications-A review. 1. Background and general mechanical-properties. Sampe J. 1995, 31, 23-31.

7. Lawcock, G.; Ye, L.; Mai, C.Y. Novel fiber-reinforced metal laminates for aerospace applications. 2. Notched strength and fatigue behavior. Sampe J. 1995, 31, 67-75.

8. Henderson, J. Fibre-reinforced-polymer composites make the leap from aerospace to infrastructure. Proc. Inst. Civ. Eng. Civ. Eng. 2014, 167, 148. [CrossRef]

9. Aamir, M.; Tolouei-Rad, M.; Giasin, K.; Nosrati, A. Recent advances in drilling of carbon fiber-reinforced polymers for aerospace applications: A review. Int. J. Adv. Manuf. Technol. 2019, 105, 2289-2308. [CrossRef]

10. Samanta, A.K. Fibre reinforced composites: Multiplicity of application. Latest Trends Text. Fash. Des. 2018, 1, 1-3. [CrossRef]

11. Prashanth, S.; Subbaya, K.M.; Nithin, K.; Sachhidananda, S. Fiber reinforced composites-A review. J. Mater. Sci. Eng. 2017, 6, 341. [CrossRef]

12. Kiani, K.; Nikkhoo, A.; Mehri, B. Prediction capabilities of classical and shear deformable beam models excited by a moving mass. J. Sound Vib. 2009, 320, 632-648. [CrossRef]

13. Kiani, K.; Mehri, B. Assessment of nanotube structures under a moving nanoparticle using nonlocal beam theories. J. Sound Vib. 2010, 329, 2241-2264. [CrossRef]

14. Kiani, K. Application of nonlocal beam models to double-walled carbon nanotubes under a moving nanoparticle. Part I: Theoretical formulations. Acta Mech. 2010, 216, 165-195. [CrossRef]

15. Kiani, K. Application of nonlocal beam models to double-walled carbon nanotubes under a moving nanoparticle. Part II: Parametric study. Acta Mech. 2011, 216, 197-206. [CrossRef]

16. Yas, H.M.; Heshmati, M. Dynamic analysis of functionally graded nanocomposite beams reinforced by randomly oriented carbon nanotube under the action of moving load. Appl. Math. Model. 2012, 36, 1371-1394. [CrossRef]

17. Khalili, S.; Jafari, A.; Eftekhari, S. A mixed Ritz-DQ method for forced vibration of functionally graded beams carrying moving loads. Compos. Struct. 2010, 92, 2497-2511. [CrossRef]

18. Yan, T.; Kitipornchai, S.; Yang, J.; He, X.Q. Dynamic behaviour of edge-cracked shear deformable functionally graded beams on an elastic foundation under a moving load. Compos. Struct. 2011, 93, 2992-3001. [CrossRef]

19. Teoh, L.; Huang, C.-C. The vibration of beams of fibre reinforced material. J. Sound Vib. 1977, 51, 467-473. [CrossRef]

20. Eksi, S.; Kapti, A.O.; Genel, K. Buckling behavior of fiber reinforced plastic-metal hybrid-composite beam. Mater. Des. 2013, 49, 130-138. [CrossRef] 
21. Allien, J.V.; Kumar, H.; Desai, V. Semi-active vibration control of SiC-reinforced Al6082 metal matrix composite sandwich beam with magnetorheological fluid core. Proc. Inst. Mech. Eng. Part L 2019, 234, 408-424. [CrossRef]

22. Jin, Q.; Ren, Y.; Peng, F.; Jiang, H. Imperfection sensitivity of free vibration of symmetrically/anti-symmetrically laminated FRC beams in thermally pre-and post-buckling equilibrium states. Acta Astronaut. 2020, 173, 240-251. [CrossRef]

23. Akbaş, S..D. Post-buckling analysis of a fiber reinforced composite beam with crack. Eng. Fract. Mech. 2019, 212, 70-80. [CrossRef]

24. Akbas, S.D. Large deflection analysis of a fiber reinforced composite beam. Steel Compos. Struct. 2018, 27, 567-576. [CrossRef]

25. Akbas, S.D. Nonlinear behavior of fiber reinforced cracked composite beams. Steel Compos. Struct. 2019, 30, 327-336. [CrossRef]

26. Nayak, S.; Pattnaik, S.; Panigrahi, I.; Nayak, R.; Panda, S. Small delamination detection in carbon fibre reinforced polymer composite beam by NDT and vibration analysis. Indian J. Eng. Mater. Sci. 2020, 27, 789-794.

27. Liu, B.; Sun, Y. Free vibration analysis of carbon-fiber-reinforced Miuraori core sandwich beam: Theoretical prediction and numerical simulation. Mech. Adv. Mater. Struct. 2020, 1-10. [CrossRef]

28. Ebrahimi, F.; Dabbagh, A. Vibration analysis of graphene oxide powder-/carbon fiber-reinforced multi-scale porous nanocomposite beams: A finite-element study. Eur. Phys. J. Plus 2019, 134, 225. [CrossRef]

29. Barretta, R.; Luciano, R.; Willis, J.R. On torsion of random composite beams. Compos. Struct. 2015, 132, 915-922. [CrossRef]

30. Reddy, J.N.; Pang, S.D. Nonlocal continuum theories of beams for the analysis of carbon nanotubes. J. Appl. Phys. 2008, 103, 023511. [CrossRef]

31. Liew, K.; Lei, Z.; Zhang, L. Mechanical analysis of functionally graded carbon nanotube reinforced composites: A review. Compos. Struct. 2015, 120, 90-97. [CrossRef]

32. Akgöz, B.; Civalek, Ö. Bending analysis of embedded carbon nanotubes resting on an elastic foundation using strain gradient theory. Acta Astronaut. 2016, 119, 1-12. [CrossRef]

33. Civalek, Ö.; Uzun, B.; Yayli, M.Ö.; Akgöz, B. Size-dependent transverse and longitudinal vibrations of embedded carbon and silica carbide nanotubes by nonlocal finite element method. Eur. Phys. J. Plus 2020, 135, 1-28. [CrossRef]

34. Vodenitcharova, T.; Zhang, L. Bending and local buckling of a nanocomposite beam reinforced by a single-walled carbon nanotube. Int. J. Solids Struct. 2006, 43, 3006-3024. [CrossRef]

35. Ke, L.-L.; Yang, J.; Kitipornchai, S. Nonlinear free vibration of functionally graded carbon nanotube-reinforced composite beams. Compos. Struct. 2010, 92, 676-683. [CrossRef]

36. Yas, M.; Samadi, N. Free vibrations and buckling analysis of carbon nanotube-reinforced composite Timoshenko beams on elastic foundation. Int. J. Press. Vessel. Pip. 2012, 98, 119-128. [CrossRef]

37. Wattanasakulpong, N.; Ungbhakorn, V. Analytical solutions for bending, buckling and vibration responses of carbon nanotubereinforced composite beams resting on elastic foundation. Comput. Mater. Sci. 2013, 71, 201-208. [CrossRef]

38. Vo-Duy, T.; Ho-Huu, V.; Nguyen-Thoi, T. Free vibration analysis of laminated FG-CNT reinforced composite beams using finite element method. Front. Struct. Civ. Eng. 2019, 13, 324-336. [CrossRef]

39. Shafiei, H.; Setoodeh, A.R. An analytical study on the nonlinear forced vibration of functionally graded carbon nano-tubereinforced composite beams on nonlinear viscoelastic foundation. Arch. Mech. 2020, 72, 81-107. [CrossRef]

40. Mohammadimehr, M.; Monajemi, A.A.; Afshari, H. Free and forced vibration analysis of viscoelastic damped FG-CNT reinforced micro composite beams. Microsyst. Technol. 2017, 26, 1-15. [CrossRef]

41. Lin, F.; Xiang, Y. Vibration of carbon nanotube reinforced composite beams based on the first and third order beam theories. Appl. Math. Model. 2014, 38, 3741-3754. [CrossRef]

42. Khosravi, S.; Arvin, H.; Kiani, Y. Vibration analysis of rotating composite beams reinforced with carbon nanotubes in thermal environment. Int. J. Mech. Sci. 2019, 164, 105187. [CrossRef]

43. Civalek, Ö.; Akbaş, Ş.; Akgöz, B.; Dastjerdi, S. Forced vibration analysis of composite beams reinforced by carbon nanotubes. Nanomaterials 2021, 11, 571. [CrossRef]

44. Ansari, R.; Shojaei, M.F.; Mohammadi, V.; Gholami, R.; Sadeghi, F. Nonlinear forced vibration analysis of functionally graded carbon nanotube-reinforced composite Timoshenko beams. Compos. Struct. 2014, 113, 316-327. [CrossRef]

45. Karami, B.; Janghorban, M.; Shahsavari, D.; Dimitri, R.; Tornabene, F. Nonlocal buckling analysis of composite curved beams reinforced with functionally graded carbon nanotubes. Molecules 2019, 24, 2750. [CrossRef]

46. Fallah, A.; Dehkordi, M.B.; Nourbakhsh, H.; Beni, Y.T. Semi-exact solution for nonlinear dynamic analysis of graded carbon nanotube-reinforced beam with graded shape memory wires. Mech. Adv. Mater. Struct. 2021, 28, 568-582. [CrossRef]

47. Kiani, Y.; Mirzaei, M. Nonlinear stability of sandwich beams with carbon nanotube reinforced faces on elastic foundation under thermal loading. Proc. Inst. Mech. Eng. Part C 2018, 233, 1701-1712. [CrossRef]

48. Babaei, H.; Kiani, Y.; Eslami, M.R. Thermomechanical analysis of large deflection in shear deformable FG-CNT reinforced composite beams using perturbation technique. Math. Methods Appl. Sci. 2021. [CrossRef]

49. Civalek, Ö.; Dastjerdi, S.; Akbaş, Ş.D.; Akgöz, B. Vibration analysis of carbon nanotube-reinforced composite microbeams. Math Methods Appl. Sci. 2021, 11, 571. [CrossRef]

50. Wang, Y.; Xie, K.; Fu, T. Vibration analysis of functionally graded graphene oxide-reinforced composite beams using a new Ritz-solution shape function. J. Braz. Soc. Mech. Sci. Eng. 2020, 42, 1-14. [CrossRef]

51. Song, M.; Gong, Y.; Yang, J.; Zhu, W.; Kitipornchai, S. Free vibration and buckling analyses of edge-cracked functionally graded multilayer graphene nanoplatelet-reinforced composite beams resting on an elastic foundation. J. Sound Vib. 2019, 458, 89-108. [CrossRef] 
52. Mojiri, H.R.; Salami, S.J. Free vibration and dynamic transient response of functionally graded composite beams reinforced with graphene nanoplatelets (GPLs) resting on elastic foundation in thermal environment. Mech. Based Des. Struct. Mach. 2020, 1-21. [CrossRef]

53. Nematollahi, M.S.; Mohammadi, H.; Dimitri, R.; Tornabene, F. Nonlinear vibration of functionally graded graphene nanoplatelets polymer nanocomposite sandwich beams. Appl. Sci. 2020, 10, 5669. [CrossRef]

54. Vinson, J.R.; Sierakowski, R.L. Behaviour of Structures Composed of Composite Materials, 2nd ed.; Kluwer Academic Publishers: Amsterdam, The Netherlands, 2002; ISBN 978-140-2009-04-4.

55. Krawczuk, M.; Ostachowicz, W.; Żak, A. Modal analysis of cracked, unidirectional composite beam. Compos. Part B Eng. 1997, 28, 641-650. [CrossRef]

56. Tao, C.; Fu, Y.-M.; Dai, H.-L. Nonlinear dynamic analysis of fiber metal laminated beams subjected to moving loads in thermal environment. Compos. Struct. 2016, 140, 410-416. [CrossRef] 